\title{
Correlation of expressions of S100A8 and S100A9 and its prognostic potential in nasopharyngeal carcinoma
}

\author{
Wenbing $\mathrm{Hu}^{1}$, Gangsheng Wang ${ }^{2}$, Lun $\mathrm{Ye}^{2}$, Jun Chen ${ }^{2}, \mathrm{Xi} \mathrm{Chen}{ }^{2}$, Lei $\mathrm{Gu}^{2}$ and \\ Zezhang Tao ${ }^{1 *}$ \\ ${ }^{1}$ Department of Otolaryngology-Head and Neck Surgery, Renmin Hospital of Wuhan University, Wuhan 430060, ${ }^{2}$ Department of \\ Oncology, Central Hospital of Huangshi City of Edong Healthcare, Huangshi 435000, China
}

*For correspondence: Email: ok0457@163.com

Sent for review: 5 July 2017

Revised accepted: 17 October 2017

\begin{abstract}
Purpose: To investigate the expressions of S100 calcium-binding proteins A8 (S100A8) and S100 A9 (S100A9) in nasopharyngeal carcinoma (NPC) tissues and their correlation with clinical pathological characteristics and prognosis of NPC.

Methods: Ninety-two NPC tissue samples and 92 nasopharyngitis tissue samples (controls) were collected. All the NPC patients were on follow-up for more than 5 years. The expressions of S100A8 and S100A9 were determined in these tissues by immunohistochemistry. The relationship between the expressions of S100A8 and S100A9, and the clinico-pathological features were analyzed by Spearman correlation analysis, and the results evaluated by Kaplan-Meier method.

Results: The differences between their expressions in the two tissues were statistically significant $(p<$ $0.05)$. Neither gender nor age was associated with expressions of S100A8 and S100A9 ( $p>0.05)$, but they were closely related to the degree of differentiation, clinical stages and metastasis of lymph node $(p<0.05)$. The expression of S100A8 had significant positive correlation with the expression of S100A9 $(r=0.393, p=0.000)$. Prognosis of patients with positive expressions of S100A8 and S100A9 was poor, when compared to patients with negative expressions of these proteins $(p<0.05)$.

Conclusion: Expressions of S100A8 and S100A9 are closely related to the development of NPC. High expressions of the two proteins may have an important influence in the progress of tumor invasion but are associated with poor prognosis of NPC. These findings could be significant indicators of early diagnosis, effectiveness of treatment and prognosis of NPC.
\end{abstract}

Keywords: S100A8, S100A9, Calcium-binding proteins, Prognosis, Nasopharyngeal carcinoma, Prognosis

Tropical Journal of Pharmaceutical Research is indexed by Science Citation Index (SciSearch), Scopus, International Pharmaceutical Abstract, Chemical Abstracts, Embase, Index Copernicus, EBSCO, African Index Medicus, JournalSeek, Journal Citation Reports/Science Edition, Directory of Open Access Journals (DOAJ), African Journal Online, Bioline International, Open-J-Gate and Pharmacy Abstracts

\section{INTRODUCTION}

Nasopharyngeal carcinoma (NPC) usually occurs on the top, or in the lateral wall of the nasopharynx. It is a malignant head and neck tumor associated with high incidence and fatality rate $[1,2]$. The primary treatment for NPC is radiation therapy, but the clinical effect of this therapy is not satisfactory because of high rate of local recurrence and metastasis. The survival rate of 5 years after treatment of patients in stage 1 NPC may be up to $95 \%$ after combined therapy, but the survival rate of 5 years after treatment for stage IV patients is merely $35 \%$ [3]. Thus, it is important to improve early diagnosis and search for new therapeutic targets and prognostic indicators of NPC.

S100 proteins belong to the family of calcium- 
binding proteins with low molecular weight. All members of this family have special spatial structures that enable them bind calcium ions, and are involved in signal transduction [4,5]. S100 calcium-binding protein A8 and $\$ 100$ calcium-binding protein A9 genes are both located on the long arm of chromosome 1 (1q21) with the characteristic helical annular and EF-hand structures of S100 protein family [6]. However, chromosomal deletions, translocations and overlaps are more common due to weak stability of this bond of chromosome [7]. S100A8 is an active pro-inflammatory calcium binding protein composed of 267 bases encoding 88 residues. S100A9 exhibits various biological activities such as regulation of cell growth and proliferation, protein phosphorylation, inflammatory reactions and cell migration $[8,9]$.

Studies in recent years have reported that S100A8 and S100A9 are implicated in the pathogenesis and development of tumors, especially in metastasis of tumor cells and induction of immune suppression [10-12]. However S100A8 and S100A9 have different functions and modes of action in different tumor cells. Moreover the exact roles of the two proteins in NPC have not been elucidated.

In this study, the expressions of S100A8 and S100A9 in NPC were measured by immunohistochemistry. The data were analyzed for any correlation with clinical pathological characteristics, and prognosis of NPC.

\section{EXPERIMENTAL}

\section{General material}

NPC tissue samples of 92 patients were collected in the Head and Neck Surgery unit of the Department of Otolaryngology, Renmin Hospital of Wuhan University, and Department of Oncology in Central Hospital of Huangshi City of Edong Healthcare, from January 2008 to December 2011. The study was approved by Ethics Committee of The Renmin Hospital of Wuhan University, (approval no. WH200170024), and followed the guidelines of Declaration of Helsinki promulgated in 1964 as amended in 1996 [13]. All the patients agreed to participate in this study and signed informed consent. There were 58 males and 34 females, who aged from 22 to 67 years (mean age $=50.76 \pm 9.42$ years). There were 74 cases of low differentiation and 18 cases of middle or high differentiation. Based on 2008 UICC/AJCC staging standards, 48 cases were in stages I and II, while 44 cases were in stages III and IV. Lymph node metastasis occurred in 63 cases, but was absent in 29 cases. In addition, 92 chronic nasopharyngitis tissue samples were collected at the same period, as control. There were 55 males and 37 females in the control group, aged from 21 to 65 years (mean age $=50.42 \pm 9.36$ years). The differences between baseline data of the two groups showed no statistical significance $(p>$ 0.05).

\section{Inclusion and exclusion criteria}

The inclusion criteria included patients diagnosed by $\mathrm{MRI} / \mathrm{CT}$ and pathological examination, patients who were not on radiation therapy or chemotherapy, or any other form of treatment; patients with KPS scores $\geq 70$, and patients with complete clinical and pathological data.

Patients with a history of other organ tumors, patients diagnosed with serious heart, brain, lung and kidney diseases, pregnant or breastfeeding patients, and patients who were unwilling to participate in the follow-up study, were all excluded.

\section{Immunohistochemistry assays}

NPC tissue samples were fixed in $10 \%$ methanol, paraffin-embedded, sectioned and then de-waxed. The tissue biopsies were placed in boiling citric acid buffer ( $\mathrm{pH} 6.0)$, and heated continuously for $15 \mathrm{~min}$ by microwave to repair the antigen, incubated in the deionized water of 3 $\%$ hydrogen peroxide for $15 \mathrm{~min}$ at $37{ }^{\circ} \mathrm{C}$. The first antibodies (rabbit anti-human S100A8 and S100A9 monoclonal antibodies (Abcam Company, UK) were added, incubated for $60 \mathrm{~min}$ at $37{ }^{\circ} \mathrm{C}$ and incubated at $4{ }^{\circ} \mathrm{C}$ overnight. Then the second antibody (SP kit, Abcam Company, UK) was added, and incubated for $45 \mathrm{~min}$ at 37 ${ }^{\circ} \mathrm{C}$. Thereafter streptavidin-peroxidase (S-P) was added, and the complex was incubated for 45 min at $37{ }^{\circ} \mathrm{C}$, and stained with BAD, then again with hematoxylin. This positive tissue section was used as positive control, while in the negative control, the first antibody was replaced with citrate buffer.

Expressions of S100A8 and S100A9 were located in cytoplasm and cell nucleus. Couple score and semi-ration score criterion were performed to evaluate the results. Ten (10) visual fields were randomly selected under optical microscope $(x 400)$ and 100 cells were sequentially counted for each field. The staining intensity of tumor cells and percentage of positive cells were evaluated, and positive expression was judged by the total score of staining intensity and positive cells. The scoring criteria for staining intensity were: 0 or 1 for pale 
yellow, 2 for brownish-yellow, and 3 for tan. Positive cells were scored as follows: 0 for $<6 \%$ positive cells; 1 for 6 - $25 \%$ positive cells; 2 for 26 - $50 \%$ positive cells; 3 for 51 - $75 \%$ positive cells; and 4 for $>75 \%$ positive cells. The scores for staining intensity and positive cells were combined, and classified as follows: score of 0 1 was negative expression (-); scores of 2 - 3 were categorized as weakly positive expression $(+)$; scores of $4-5$ indicated mildly positive expression $(++)$, while scores of $6-7$ were deemed as indicative of strongly positive expression (+++).

\section{Statistical analysis}

Measurement data are expressed as mean \pm standard deviation (SD) and $t$ test was used for the comparison between means. The results from enumeration were expressed as percentage (\%) and $X^{2}$ test was used for the comparison. Data were analyzed statistically by SPSS 22.0 software. Spearman correlation analysis was used to analyze association of the expressions of S100A8 and S100A9. Kaplan-Meier method was applied to analyze survival data. $P<0.05$ indicated that differences were statistically significant.

\section{RESULTS}

\section{Comparison of expressions of S100A8 and S100A9 in NPC and nasopharyngitis tissues}

The positive expressions of S100A8 and S100A9 were 52.17 and $72.83 \%$, respectively in NPC tissue, and 17.39 and 36.96, respectively in nasopharyngitis tissue (Table 1 ). The differences in the expressions of these proteins between the two tissues were statistically significant $(p<$ 0.05).

\section{Relationship between expressions of S100A8 and S100A9, and clinical pathology}

Neither gender nor age was associated with the expressions of S100A8 and S100A9 $(P>0.05)$, but they had closely relation to the degree of differentiation, TNM system and lymph node metastasis ( $p<0.05$, Table 2$)$.

Table 1: Comparison of the expressions of S100A8 and S100A9 in NPC and nasopharyngitis tissues $\{(\mathrm{n}(\%)\}$

\begin{tabular}{lccccc}
\hline \multirow{2}{*}{ Group } & No. of & \multicolumn{2}{c}{ Expression of S100A8 } & \multicolumn{2}{c}{ Expression of S100A9 } \\
\cline { 3 - 6 } & cases & - & $+\sim+++$ & - & $+\sim+++$ \\
\hline NPC tissue & 92 & $44(47.83)$ & $48(52.17)$ & $25(27.17)$ & $67(72.83)$ \\
Nasopharyngitis tissue & 92 & $76(82.61)$ & $16(17.39)$ & $58(63.04)$ & $34(36.96)$ \\
$X^{2}$ & - & & 24.533 & & 23.903 \\
$P$ & - & & 0.000 & & 0.000 \\
\hline
\end{tabular}

Table 2: Relationship between the expressions of S100A8 and S100A9, and clinical pathology $\{\mathrm{n}(\%)\}$

\begin{tabular}{|c|c|c|c|c|c|c|c|}
\hline \multirow{2}{*}{ Correlation factor } & \multirow{2}{*}{$\begin{array}{l}\text { No. of } \\
\text { cases }\end{array}$} & \multicolumn{2}{|c|}{ S100A8 } & \multirow{2}{*}{$\boldsymbol{X}^{2} / \boldsymbol{P}$ value } & \multicolumn{2}{|c|}{ S100A9 } & \multirow[t]{2}{*}{$x^{2} / P$-value } \\
\hline & & - & $+\sim+++$ & & - & $+\sim+++$ & \\
\hline Gender & & & & $0.565 / 0.452$ & & & $0.136 / 0.712$ \\
\hline Male & 58 & $26(44.83)$ & $32(55.17)$ & & $15(25.86)$ & $43(74.14)$ & \\
\hline Female & 34 & $18(52.94)$ & $16(47.06)$ & & $10(29.41)$ & $24(70.59)$ & \\
\hline Age & & & & $2.630 / 0.105$ & & & $1.620 / 0.203$ \\
\hline$<60$ years & 38 & $22(57.89)$ & $16(42.11)$ & & $13(34.21)$ & $25(65.79)$ & \\
\hline$\geq 60$ years & 54 & $22(40.74)$ & $32(59.62)$ & & $12(22.22)$ & $42(77.78)$ & \\
\hline $\begin{array}{l}\text { Degree of } \\
\text { differentiation }\end{array}$ & & & & $8.046 / 0.005$ & & & $4.545 / 0.033$ \\
\hline Low differentiation & 74 & $30(40.54)$ & $44(59.46)$ & & $16(21.62)$ & $58(78.38)$ & \\
\hline $\begin{array}{l}\text { Middle or high } \\
\text { differentiation }\end{array}$ & 18 & $14(77.78)$ & $4(22.22)$ & & $9(50.00)$ & $9(50.00)$ & \\
\hline TNM system & & & & $8.661 / 0.003$ & & & $5.408 / 0.020$ \\
\hline $\mathrm{I} \sim \mathrm{II}$ & 48 & $30(62.50)$ & $18(37.50)$ & & $18(37.50)$ & $30(62.50)$ & \\
\hline III $\sim$ VV & 44 & $14(31.82)$ & $30(68.18)$ & & $7(15.91)$ & 37 (84.09) & \\
\hline $\begin{array}{l}\text { Lymph } \\
\text { node metastasis }\end{array}$ & & & & $10.260 / 0.001$ & & & $12.898 / 0.000$ \\
\hline Yes & 63 & $23(36.51)$ & $40(63.49)$ & & $10(15.87)$ & $53(84.13)$ & \\
\hline No & 29 & $21(72.41)$ & $8(27.59)$ & & $\begin{array}{r}15 \\
51.72)\end{array}$ & $14(48.28)$ & \\
\hline
\end{tabular}


Correlation analysis of expressions of S100A8 and S100A9 in NPC tissues

Spearman correlation analysis indicated that the expression of S100A8 was significantly and positively correlated with the expression of S100A9 ( $r=0.393, p=0.000$, Table 3).

\section{Relationship between expressions of S100A8 and S100A9, and prognosis}

All the patients were followed up for more than 5 years. Based on the expressions of S100A8 and S100A9, the 92 patients were divided into 4 groups, consisting of 20 cases of S100A8(-) and S100A9(-) which were placed in group A (1 case was lost during follow- up, while 19 cases completed follow-up); 24 cases of S100A8(-) and S100A9(+) were put in group B (2 cases were lost during follow-up, while 22 cases completed follow-up); 5 cases of S100A8(+) and S100A9(-) were placed in group $C$ (no cases lost during follow-up); 43 cases of S100A8(+) and S100A9(+) were put in group D (5 cases lost to follow up, 38 cases completed follow up). The results of overall survival patients in each group are shown in Kaplan-Meier survival curves (Figure 1). Results (log-rank test) showed significant differences in survival time among the
4 groups $\left(x^{2}=10.336, p=0.016\right)$. Subsequently, Bonferroni's test was used to compare the groups, and the results indicated that group $A$ was significantly higher than group $\mathrm{D}\left(x^{2}=8.378\right.$, $p=0.004$ ), but no significant differences were seen between any other two groups (group A vs group $B: x^{2}=1.937, p=0.164$; group A vs group $C: X^{2}=1.590, p=0.207$; group $B$ vs group $C: X^{2}=0.250, p=0.617$; group $B$ vs group $D: X^{2}=3.306, p=0.069$; group $C$ vs group $\left.\mathrm{D}: x^{2}=0.402, p=0.526\right)$.

\section{DISCUSSION}

S100 proteins are small molecular weight calcium-binding proteins. S100A8 and S100A9 are two monomeric proteins, encoded by genes located on chromosome 1q21 as part of the S100 gene cluster. Chromosome 1q21 is a region with poor stability due to chromosomal deletions, translocations and overlaps. Research has shown that the chromosomal changes in this region are closely related to incidence of cancer [14]. Under normal physiological conditions, S100A8 and S100A9 are secreted in the cytoplasm by myeloid cells such as monocytes, neutrophils and macrophages.

Table 3: Correlation analysis of the expressions of S100A8 and S100A9 in NPC tissues

\begin{tabular}{lrrr}
\hline Item & S100A9 (-) & S100A9 (+) & Total \\
\hline S100A8 (-) & 20 & 24 & 44 \\
S100A8 (+) & 5 & 43 & 48 \\
Total & 25 & 67 & 92 \\
\hline
\end{tabular}

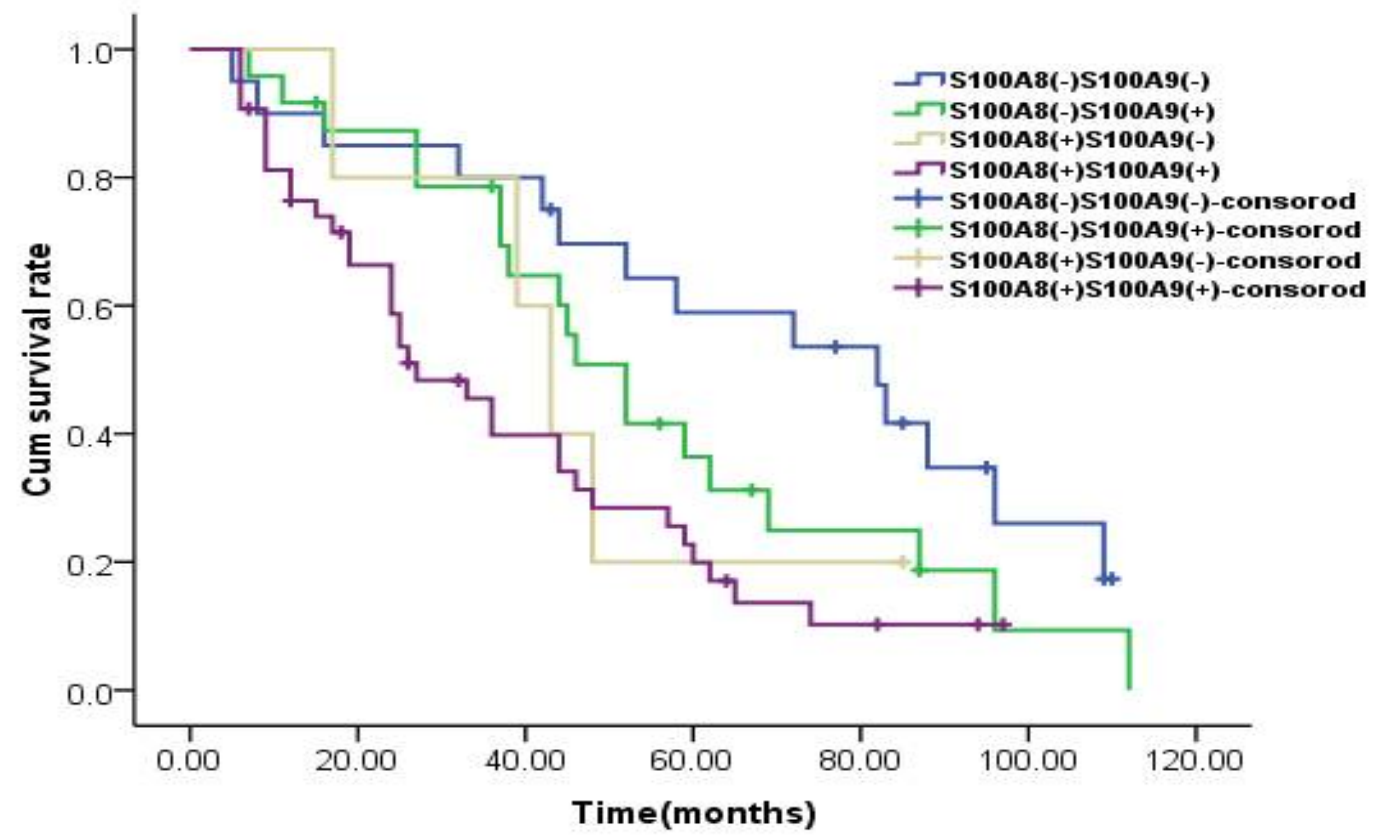

Figure 1: Overall survival (OS) of patients as a function of expressions of S100A8 and S100A9 
However, the two proteins can also be secreted by epithelia, keratinocytes and endotheliocytes under pathological conditions, and transferred to membranes, cytoskeletons or outside the cell $[15,16]$.

Results from recent studies suggest that the expressions of S100A8 and S100A9 were upregulated in most malignant tumor cells, and are related to the formation, infiltration and metastasis of carcinoma [17]. In this study, the expressions of S100A8 and S100A9 in NPC tissue, and in chronic nasopharyngitis tissue was determined immunohistochemically. The results showed that these expressions were significantly higher in NPC than in nasopharyngitis tissues. Hermani et al [18] have reported that cell growth can be promoted by glycation end-products receptor (RAGE), a process which also activates the phosphorylation activity of mitogen-activated protein kinase (MAPK) and the pathway of nuclear factor-kB (NF-kB), thereby leading to cell proliferation. Thus, the increased expression of S100A8 and S100A9 in NPC tissues may induce tumor cell proliferation.

Han et al [19] reported that the serum levels of S100A8 and S100A9 in NPC patients were significantly higher than those of healthy persons. Moreover, Kim et al [17] found significant increases in S100A8 and S100A9 in the plasma of patients with colorectal cancer, and suggested that these can serve as serum markers in the clinical diagnosis of colorectal cancer. This is in agreement with the results obtained in the present study which showed that S100A8 and S100A9 had closely correlation with the degree of differentiation, stage of TNM system and lymph node metastasis, indicating that the expressions of S100A8 and S100A9 increase with the degree of malignancy of NPC. However, there was no close relationship between the expressions of S100A8 and S100A9, and the gender and age of the NPC patients. Studies by Lim et al.[20] showed that monocytes and macrophages in the microenvironment of metastatic liver cells induced the formation of S100A8 and S100A9, and that these two proteins influenced the migration and invasion of tumor cells.

Results of correlation analysis in this study showed that the expression of S100A8 had low correlation with the expression of S100A9, which indicated that the two proteins may have synergistic effects on the formation and development of NPC. S100A8 and S100A9 form S100A8 -S100A9 heterodimer complex in a calcium-dependent process [21-23]. In the S100A8-S100A9 complex, S100A8 is the main bioactive protein, while S100A9 serves to ensure the stability of the complex by regulating S100A8 $[24,25]$. The results of survival analysis (KaplanMeier) also indicated a synergy in the expressions of S100A8 and S100A9. The prognosis of patients with positive expressions of S100A8 and S100A9 was poorer than that of patients with negative expressions of S100A8 and S100A9. This suggests that S100A8 and S100A9 genes can be used as predictors of prognosis of nasopharyngeal carcinoma.

Through gene expression profiling, Moon et al [26] reported that S100A8 and S100A9 genes were potential indicators of the metabolic state of mammary epithelial cells, which can be potential targets for treating breast cancer and predicting prognosis. Results obtained by Wang et al [11] suggested that increased levels of myeloidderived suppressor cells (MDSCs) from bone marrow were closely related to increased clinical incidence of gastric cancer, and declines in survival rate. S100A8 and S100A9 could be potential indicators of immunosuppressive function induced by MDSCs of cancer patients. In this study, the expressions of S100A8 and S100A9 (for negative survival rate) showed no significant difference with positive survival rate of expression of either protein. However the survival curves showed distinct differences in survival rate between these two groups.

\section{CONCLUSION}

The expressions of S100A8 and S100A9 in NPC tissues are fairly high. The expression of the two proteins are also positively correlated with severity of NPC, and thus indicate poor prognosis of the disease. These findings suggest that S100A8 and S100A9 could be significant indicators of early diagnosis, treatment effectiveness and prognosis of NPC.

\section{DECLARATIONS}

\section{Acknowledgement}

None provided.

\section{Conflict of Interest}

No conflict of interest associated with this work.

\section{Contribution of Authors}

The authors declare that this work was done by the authors named in this article and all liabilities pertaining to claims relating to the content of this article will be borne by them. 


\section{Open Access}

This is an Open Access article that uses a funding model which does not charge readers or their institutions for access and distributed under the terms of the Creative Commons Attribution License (http://creativecommons.org/licenses/by/ 4.0) and the Budapest Open Access Initiative (http://www.budapestopenaccessinitiative.org/rea d), which permit unrestricted use, distribution, and reproduction in any medium, provided the original work is properly credited.

\section{REFERENCES}

1. Parkin DM, Bray MF, Ferlay MJ, Pisani P. Global Cancer Statistics, 2002. CA Cancer J Clin 2005; 55(2): 74-108.

2. Carioli G, Negri E, Kawakita D, Garavello W, La Vecchia C, Malvezzi M. Global trends in nasopharyngeal cancer mortality since 1970 and predictions for 2020: Focus on low-risk areas. Int J Cancer 2017; 140(10): 2256-2264.

3. Peirong Jia ZY, Zheng Jun. The expression of ARD1 in nasopharyngeal carcinoma and its clinical significance. Chongqing Med J 2016; 45(2): 183-188.

4. Bresnick AR, Weber DJ, Zimmer DB. S100 proteins in cancer. Nat Rev Cancer 2015; 15(2): 96-109.

5. Pruenster M, Vogl T, Roth J, Sperandio M. S100A8/A9: From basic science to clinical application. Pharmacol Ther 2016; 167: 120-131.

6. Korndörfer IP, Brueckner F, Skerra A. The Crystal Structure of the Human (S100A8/S100A9) 2 Heterotetramer, Calprotectin, Illustrates how Conformational Changes of Interacting $\alpha$-Helices Can Determine Specific Association of Two EF-hand Proteins. J Mol Biol 2007; 370(5): 887-898.

7. Lodeiro $M$, Puerta $E$, Ismail MA, Rodriguezrodriguez $P$, Rönnbäck A, Codita A, Parradofernandez C, Maioli $S$, Gilbea $F$, Merinoserrais $P$. Aggregation of the Inflammatory S100A8 Precedes A $\beta$ Plaque Formation in Transgenic APP Mice: Positive Feedback for S100A8 and $A \beta$ Productions. J Gerontol 2016: 72(3): 319-328.

8. Blanco-Rojo R, Delgado-Lista J, Lee YC, Lai CQ, PerezMartinez $P$, Rangel-Zuñiga $O$, Smith $C E$, Hidalgo $B$, Alcala-Diaz JF, Gomez-Delgado F. Interaction of an S100A9 gene variant with saturated fat and carbohydrates to modulate insulin resistance in 3 populations of different ancestries. Am J Clin Nutr 2016; 104(2): 508-517.

9. Zefeng Huo $\mathrm{MH}$, Xiaofeng Duan. The expression of S100A9 in OSCC and its clinical significance. J Otolaryngol Head Neck Surg 2017; 31(3): 219-222.

10. Moris $D$, Spartalis E, Angelou A, Margonis GA, Papalambros A, Petrou A, Athanasiou A, Schizas $D$, Dimitroulis $D$, Felekouras $E$. The value of calprotectin S100A8/A9 complex as a biomarker in colorectal cancer: A systematic review. Journal of B.u.on. J BUON 2016; 21(4): 859-866.
11. Wang L CE, Wong SC. Increased myeloid-derived suppressor cells in gastric cancer correlate with cancer stage and plasma S100A8/A9 proinflammatory proteins. J Immunol 2013; 190(2): 794-804.

12. Yun SJ, Yan C, Jeong $P$, Kang HW, Kim YH, Kim EA, Lee OJ, Kim WT, Moon SK, Kim IY. Comparison of $m R N A$, Protein, and Urinary Nucleic Acid Levels of S100A8 and S100A9 between Prostate Cancer and BPH. Ann Surg Oncol 2015; 22(7): 2439-2445.

13. World Health Organization. Declaration of Helsinki. Br Med J 1996; 313(7070): 1448-1449.

14. Srikrishna G. S100A8 and S100A9: new insights into their roles in malignancy. $J$ Innate Immun 2012; 4(1): 31-40.

15. Leśniak W. Epigenetic regulation of $\$ 100$ protein expression. Clin Epigenetics 2011; 2(2): 77-83.

16. Yantao Zou GY, Tang Ying. Transcriptional regulation of S100A8/A9 human gene. Chemistry of Life 2016; 36(3): 293- 297.

17. Kim HJ, Kang HJ, Lee H, Lee ST, Yu MH, Kim H, Lee C. Identification of S100A8 and S100A9 as serological markers for colorectal cancer. J Proteome Res 2009; 8(3): 1368-1379.

18. Hermani A, De SB, Medunjanin S, Tessier PA, Mayer D. S100A8 and S100A9 activate MAP kinase and NFkappaB signaling pathways and trigger translocation of RAGE in human prostate cancer cells. Exp Cell Res 2006; 312(2): 184-197.

19. Ranran Han $Y H$, Chen ling. Concentration determinations of S100A8 and S100A9 in NPC and the clinical significance. J Clin Lab Sci 2014; 32(4): 252-254.

20. Lim SY, Yuzhalin AE, Gordonweeks AN, Muschel RJ. Tumor-infiltrating monocytes/macrophages promote tumor invasion and migration by upregulating S100A8 and S100A9 expression in cancer cells. Oncogene 2016; 35(44): 5735-5745.

21. Nordal HH, Brokstad KA, Solheim M, Halse AK, Kvien TK, Hammer HB. Calprotectin (S100A8/A9) has the strongest association with ultrasound-detected synovitis and predicts response to biologic treatment: results from a longitudinal study of patients with established rheumatoid arthritis. Arthritis Res Ther 2017; 19(1): 313.

22. Moz S, Basso D, Bozzato D, Galozzi $P$, Navaglia $F$, Negm $\mathrm{OH}$, Arrigoni G, Zambon CF, Padoan A, Tighe $P$. SMAD4 loss enables EGF, TGFB1 and S100A8/A9 induced activation of critical pathways to invasion in human pancreatic adenocarcinoma cells. Oncotarget 2016; 7(43): 69927-69944.

23. Ruma IM, Putranto EW, Kondo E, Murata $H$, Watanabe $M$, Huang $P$, Kinoshita $R$, Futami J, Inoue $Y$, Yamauchi A. MCAM, as a novel receptor for S100A8/A9, mediates progression of malignant melanoma through prominent activation of NF-KB and ROS formation upon ligand binding. Clin Exp Metastasis 2016; 33(6): 609-627.

24. Xiaodan Chen JY, Wu Xin. The expression and significance of S100A8/A9 and S100A4 vulvar

Trop J Pharm Res, November 2017; 16(11): 2582 
squamous cell carcinomas. Chin J Derm Venereol 2013; 27(7): 651-653.

25. Ali $K$, Sorenson BS, Ross $K F$, Dickerson $E B$, Rifat $H$, Lingen MW, Herzberg MC. Involvement of calprotectin (S100A8/A9) in molecular pathways associated with HNSCC. Oncotarget 2016; 7(12): 14029-14047.
26. Moon A, Yong $H Y$, Song Jl, Cukovic D, Salagrama $S$, Kaplan D, Putt D, Kim H, Dombkowski A, Kim HR. Global gene expression profiling unveils S100A8/A9 as candidate markers in $\mathrm{H}$-ras-mediated human breast epithelial cell invasion. Mol Cancer Res 2008; 6(10): 1544-1553. 